RUNNING HEAD: Global Information Infrastructure

Networks of Networks: Changing Patterns in Country Bandwidth and Centrality in

Global Information Infrastructure, 2002-2010

\author{
Hyunjin Seo, Ph.D. \\ Assistant Professor \\ William Allen White School of Journalism and Mass Communications \\ The University of Kansas \\ 1435 Jayhawk Blvd. \\ Lawrence, KS 66045, USA \\ hseo@ku.edu \\ Stuart J. Thorson, Ph.D. \\ Donald P. and Margaret Curry Gregg Professor \\ The Maxwell School \\ Syracuse University \\ Syracuse, NY 13144, USA
}

Citation: Seo, H., \& Thorson, S. (2012). Networks of networks: Changing patterns in country bandwidth and centrality in global information infrastructure, 2002-2010. Journal of Communication, 62(2), 345-358. 


\title{
Networks of Networks: Changing Patterns in Country Bandwidth and Centrality in Global Information Infrastructure, 2002-2010
}

\begin{abstract}
The global distribution of information infrastructure has evolved significantly in the last decade. At a structural level, one of the most notable changes is in the way in which countries - as nodes in digital networks - link to each other. It may be analytically or epistemologically difficult to make clear causal claims between the evolution of information infrastructure and political outcomes. It may be more reasonable to argue that communications infrastructure and political processes evolve together, and in this study we attempt to measure key structural changes in bandwidth and the centrality of digital nodes, with an emphasis on Middle East and North Africa. Using a combination of bandwidth metrics and centrality indicators, we demonstrate how the information infrastructure of the Middle East and North Africa evolved between 2002 and 2010, in particular, and several countries in the Middle East rose to prominence as good nodes mediating strong intra-regional networks.
\end{abstract}

Keywords: Middle East, North Africa, information infrastructure, bandwidth, network analysis, Internet, contagion effects 


\section{Networks of Networks: Changing Patterns in Country Bandwidth and Centrality in Global Information Infrastructure, 2002-2010}

Behaviors of individuals and organizations are facilitated by characteristics of systems within which they operate (Benkler, 2011). For example, information communication technologies (ICTs) such as the internet have enabled citizens to create and share information and content without having to rely on traditional intermediaries such as government and the press. By opening new communication channels, the internet played a significant role in political and social movements (Benkler, 2006; Chadwick \& Howard, 2009; Howard, 2010). Recently, the so-called "Arab Spring" of 2010 and 2011 has raised questions about the role of ICTs and, in particular, social media. Some have argued social media helped enable these uprisings while others disagreed arguing "the revolution will not be tweeted" (Gladwell, 2010).

As Melvin Kranzberg argued, "technology is neither good nor bad, nor is it neutral" $(1985$, p. 50). It is not only activists but also dictators and oppressors who take advantage of new ICTs (Lichtenstein, 2010; Morozov, 2010). However, the fact that a system allows access to digital-based ICTs has significant implications for governance. For example, based on his empirical analysis of developing nations with significant Muslim communities, Howard (2010) concluded, "increasingly, the route to democratization is a digital one" (p. 201). While it may be too strong to argue that global changes in information infrastructure should be credited —or blamed-for social unrest, it is also a misstep to argue that this infrastructure had no role in the evolution of political protest in the Middle East. 
Increasingly, the study of contemporary political change makes reference to new patterns of communication between key actors. The most common approach to studying these changes are through the systematic analysis of content, changes in the structure of social networks in a community, or changes in the behavior of large numbers of people. At a much deeper level, the information infrastructure that connects nations is something that can also be measured. Most countries have a few internet exchange points that connect their national network infrastructure to global flows of information. Often these exchange points are operated by the state or the national telecommunications provider, but increasingly they are operated by private contractors. These exchange points relay traffic to similar infrastructure in other countries, connecting the network of domestic digital technologies to an international network of countries.

A behavioral approach to communication phenomena is certainly important, but it is also important to understand the infrastructure in which communication occurs. A reasonable discussion about social media and political change must begin with some analysis of how connectivity between countries and within regions has changed in recent years. First, we examine changes in internet connectivity over the past decade. Understanding patterns of global changes is a prerequisite to discerning those in North Africa and the Middle East. Second, we examine changes in the ways that countries in North Africa and the Middle East are connected with each other and the rest of the world. Analyzing cross-country internet connections matters as communication networks are key factors for mobilization, organization, and diffusion of political movements, and the internet has become an important communication conduit in many parts of the world (Bennett, 2004; Chadwick \& Howard, 2009; Howard, 2010; Moezzi, 2009). In the case of 
recent uprisings, there is evidence that activists in different countries shared their experiences through social media (Kirkpatrick \& Sanger, 2011). However, there remains a need for empirical analyses of how countries in the Middle East and North Africa have become woven into the fabric of the internet. Thus this study contributes to enhancing our understanding of the evolution of the internet as it relates to recent changes in the Middle East and North Africa and, more generally, political movements in the age of information technology and global networks.

\section{Networked information society and political movements}

Facilitated by increasingly available and affordable digital network-based communication tools, the ways people and organizations connect with one another have changed dramatically over the past couple of decades (Webster, 2002; Soete \& Weel, 2005; Castells, 1996, 2000, 2004; Benkler, 2006). Castells (1996, 2000, 2004) uses the term network society to describe the impact of new information and communications technologies on different levels of interactions in society. In a similar vein, Benkler (2006) argues that new digital technologies have brought about a networked information economy characterized by decentralization, nonproprietary strategies, nonmarket mechanisms, and more effective large-scale non-hierarchical cooperation. This networked information economy has resulted in an environment for public discourse where traditional mass media no longer maintain near exclusive control over "filtering" and "accreditation" (Benkler, 2006, p. 12). Citizens have become increasingly empowered to participate actively in the public sphere.

These characteristics of the networked information society have important 
implications for political and social movements. Most of all, the internet has helped change the balance of power and the levels of freedom among actors since it is more resistant to state control and censorship than most traditional forms of mass media (Benkler, 2006, 2011; Howard, 2010). This greatly helped activists mobilize and organize their movements (Bennett, 2004; Chadwick \& Howard, 2009; Howard, 2010; Moezzi, 2009). Young Egyptians were able to circumvent the state control of information by resorting to social media such as Facebook, and the result was an alternative public sphere for them. It is a shift from "the mass-mediated public sphere to a networked public sphere" (Benkler, 2006, p. 10).

Political movements in the networked information age also benefit from nonmarket peer production wherein decentralized and self-organized collaborations of individuals produce goods and services that are often made freely available to others without an expectation of direct material compensation (Benkler, 2006). During the recent events in the Middle East people in other countries collaborated with in-country protesters through online communication tools to produce and share information about the protests.

In addition, the internet helps sustain both strong and weak network links for political mobilization (Benkler, 2011; Watts \& Strogatz, 1998). Transnational network ties are facilitated, as the internet makes communication and connections between ordinary citizens in different countries more affordable and available. Social media such as Facebook and Twitter helped Egyptians protesting at Tahrir Square and those following the news through social media feel a sense of community (Kirkpatrick \& Sanger, 2011). 


\section{Global Internet Connectedness}

The internet has become a fundamental information infrastructure for contemporary social movements. Activists use digital communication tools to build and maintain social relations with and learn from their counterparts in other countries. Protesters relied on social media to share information about protest tactics and to spread inspiring stories of success (Kirkpatrick \& Sanger, 2011). Walid Rachid, a member of the April 6 Youth Movement, was quoted as saying, "Tunis is the force that pushed Egypt, but what Egypt did will be the force that will push the world" (Kirkpatrick \& Sanger, 2011, p. 1). One of the latest examples in the United States is Occupy Wall Street Movement where protesters used various forms of social media to organize the movement and keep the momentum (Ngak, 2011).

In fact, contagion or diffusion of innovation or protest waves depends on the communication network among actors (Myers, 2000; Nickerson, 2008; Valente, 1993). While it was difficult in the past to empirically study this, an ever-increasing number of online databases and significant improvements in computing power have enabled researchers to investigate complicated social networks. For example, Barnett (2001) conducted a longitudinal analysis of the international telecommunications network from 1978 to 1996 . His analysis showed that the international telecommunications network has become denser, more centralized, and highly integrated over time. An updated picture of international telecommunications networks was provided by Lee, Monge, Bar, and Matei (2007). They found that the international telecommunication network has evolved toward a decentralized structure with increased clusters within the network and increasing 
connectivity within peripheral nations.

TeleGeography's published annual surveys of internet traffic and capacity show that overall international internet bandwidth has increased from less than 5 terabytes per second (Tbps) in 2005 to about 25 Tbps in 2009, with an annual growth rate of $10 \%$ in 2005 and more than $80 \%$ in 2009 (TeleGeography, 2009). International internet bandwidth refers to the amount of data that can be transferred over the internet, across national borders, in a given amount of time. International internet bandwidth can be considered a useful indicator of global internet connectedness, especially as previous research has shown that internet bandwidth and internet traffic tend to correlate (Barnett \& Park, 2005).

Increasingly, scholars are using network analysis to identify the structure of internet-based connections among countries. For example, Townsend (2001) analyzed internet bandwidth to find that most countries have a direct internet connection with the United States, and that U.S. internet infrastructure functions as "a massive switching station for traffic that originates and terminates in foreign countries" (p. 1701). Barnett and Park's (2005) study on inter-domain hyperlinks and internet bandwidth between different countries showed similar results. The United States was the most central nation both in the hyperlink network and the international internet bandwidth network in the early 2000s. In their analysis of the structure of international internet traffic in 1998 and its correlations with other socio-cultural networks, Barnett, Chon, and Rosen (2001) found that the international internet traffic structure was significantly related to the structure of international telecommunications, trade, science, and asynchrony. Another study investigated the relationship between national culture and the structure of 
international internet linkages (Barnett \& Sung, 2005).

This paper focuses on the structure of global internet connectedness with the goal of providing a foundation for subsequent behavioral analyses of this topic. In this vein, the following research questions are investigated. How has the pattern of global internet connections changed over the past decade? Have the centrality and degree of the Middle East and North Africa (MENA) in the global internet increased over the past decade in an absolute sense and in relation to countries outside the region?

\section{Methods}

The structure of the internet connectedness is examined using network analysis - a set of procedures used to identify and measure structural properties of social systems based on relationships among entities in the system rather than on characteristics of the individual

entities (Monge \& Contractor, 2003; Newman, 2010; Rogers \& Kincaid, 1981; Wassman \& Faust, 1994). Scholars have applied the concept of the network in analyzing issues related to global connectedness, including civil society (Anheier \& Katz, 2005), transnational activism (Carpenter, 2007), international terrorism (Stohl \& Stohl, 2007), diplomatic recognition, trade (Hafner-Burton, Kahler, \& Montgomery, 2008), and international communication networks (Barnett, 2001; Barnett, Chon, \& Rosen, 2001; Barnett \& Park, 2005; Lee, Monge, Bar \& Matei, 2007).

A network can be thought of as a set of nodes together with connections or links between these nodes. In this case, the nodes are countries and the links are direct internet connections between the countries. Networks are commonly represented as graphs. A graph is directed if the edges (links between nodes) have a specific direction associated 
with them. A graph is undirected if the edges have no direction associated with them. This paper assumes that graphs representing direct internet connections are undirected since IP packets can flow in either direction through the links. Strength indicates the magnitude of the relationship and in this research it is measured by the internet bandwidth capacity of each link.

One property of a network is the number of direct links a given node has. This number is termed the degree of the node. So a node that is directly connected to five other nodes would have a degree of 5. The density of a network is a central concept for defining global connectedness. The density of a network attempts to capture how interconnected a network is by showing the ratio of actual network links to possible network links (Newman, 2010). In an undirected network, the density is calculated by this formula: $2 * \mathrm{M} /(\mathrm{V} *(\mathrm{~V}-1))$. In this formula, $\mathrm{V}$ refers to the number of nodes and $\mathrm{M}$ refers to the number of links.

Centrality measures are used to identify the most important, or "central," nodes in a network (Newman, 2010). Many different measures of centrality have been suggested, and they include degree centrality, eigenvector centrality, betweenness centrality, closeness centrality, Katz, and Page Rank centrality (for a very readable overview of centrality measures, see Newman, 2010). Degree centrality and eigenvector centrality are two of the most widely used measures. A node's degree centrality refers to the number of edges connected to it, giving one centrality point for every network neighbor a node has. Thus degree centrality is a relatively simple measure of centrality. Eigenvector centrality is more sophisticated than degree centrality and takes into account the importance, not only the number, of edges connected to a node in determining the node's centrality. So a 
node's centrality score is proportional to the sum of the scores of its neighbors.

To describe the structure of the international internet bandwidth network, the authors conducted longitudinal analyses of density, degree, and eigenvector centrality from 2002 to 2010. Graphs and statistics were calculated in R (R Development Core Team, 2011) and networks were visualized using Gephi (Bastian, Heymann, \& Jacomy, 2 009).

Global internet geography data obtained from TeleGeography were used to measure transnational internet connections. Specifically, the authors analyzed country-tocountry internet bandwidth data from 2002 to 2010. Bandwidth refers to capacity and thus is an upper bound on actual bit flows. Given the time necessary to increase capacity, bandwidth also acts as a leading indicator for traffic. It is also important to remember that while the internet is a packet switched network, the analysis in this paper focuses only on direct connections between counties. The number of countries reporting internet bandwidth greater than zero was 187 in 2002 and 201 in 2010.

\section{Results}

Analysis of internet bandwidth data identified interesting characteristics of connections among countries. First of all, the total amount of international internet bandwidth has significantly increased in a manner reminiscent of the familiar power law from 931,319 Mbps (megabytes per second) in 2002 to 37,424,671 Mbps (about 36 Tbps) in 2010. A graphic representation of the international internet bandwidth network for 2002 and 2010 based on node eigenvector centrality scores is presented in Figure 1 and Figure 2. For the brevity of presentation, only countries with connections of degree 4 or greater in each 
year are shown in the figures. In the graphs, the diameter of the node is proportional to the node's eigenvector centrality. To denote countries, ISO 3166-1 alpha-2 codes using the English short country names were used.

\section{FIGURE 1 ABOUT HERE}

The United States was the most important country in the 2002 internet network based on both eigenvector centrality and degree. The eigenvector centrality of the United States was 1 and the degree was 124 in 2002. Following the United States in terms of eigenvector centrality were the United Kingdom, Germany, France, Italy, Singapore, Netherlands, and China.

In 2010, the United States maintained the highest degree with 94, but its eigenvector centrality (0.970) was second to the United Kingdom (1). Germany, China, Singapore, and Italy followed the United States in eigenvector centrality scores. In addition, compared with the 2002 network, more countries with degree 4 or greater appeared in the 2010 network (Figure 2).

The density of the global internet network was 0.030 in 2002 and it rose to 0.034 in 2010. While the values are not much different, it is important to understand that the density was maintained at that level despite the increasing number of the countries in the global internet network. This is perhaps especially interesting in that the overall density actually increased over time (with the exception of 2002-2003) even as more countries were reporting being connected.

\section{Middle East and North Africa}

Total international internet bandwidth within the Middle East and North Africa (MENA) 
region has increased considerably between 2002 and 2010 ${ }^{1}$. The total MENA bandwidth was 2,096 Mbps in 2002 and increased to 375,798 Mbps in 2010. The growth in the internet bandwidth within the region showed a power-law pattern similar to that found in worldwide bandwidth capacity. As Figure 2 demonstrates, quite a few MENA countries moved toward the center between 2002 and 2010. These MENA countries include the United Arab Emirates, Qatar, Egypt, and Saudi Arabia.

\section{FIGURE 2 ABOUT HERE}

Figure 3 shows eigenvector centralities of MENA countries in comparison with other countries between 2002 and 2010. In Figure 3, the dotted grey line indicates the overall mean eigenvector centrality score for the given year. As shown in Figure 3, eigenvector centralities of several MENA countries have increasingly gotten greater than the overall mean eigenvector centrality of the world in 2008, 2009, and 2010. The X-axis in this figure represents the countries (nodes) in each year's dataset. The Y-axis represents eigenvector centrality scores. Dotted grey line indicates the mean eigenvector centrality score for all countries that year. Dots in black represent MENA countries. For the non-MENA countries, darker areas of grey reflect overlapping centrality scores. Figure 3 is interesting because it reveals that while the mean centrality score for all the countries in the sample has been fairly constant between 2002 and 2010, some MENA countries, such as the United Arab Emirates, Qatar, and Egypt, became more important nodes in the network over time.

In 2002, Israel showed the highest eigenvector centrality (0.207) among the 
MENA countries whose data were available. Israel was followed by the United Arab Emirates (0.202), Iran (0.192), Lebanon (0.130), Oman (0.126), Saudi Arabia (0.099), Egypt (0.099), Bahrain (0.099), Yemen (0.088), Kuwait (0.084), Qatar (0.072), Syria (0.070), Jordan (0.060), Morocco (0.052), Algeria (0.025), Libya (0.014), Palestine Territory (0.012), and Sudan (0.012). The United Arab Emirates showed the highest degree with 12, and the degree of Israel was 8. Data for Iraq and Tunisia were not available for 2002 .

By 2010, the place of MENA countries in global information infrastructure had changed in interesting ways, both relative to the important information nodes of the United States, and relative to each other. The United Arab Emirates emerged as the most important MENA country both in terms of eigenvector centrality (0.510) and degree (21). Moreover, Qatar (0.398) and Egypt (0.355) rose to become top 3 countries based on eigenvector centrality. They were followed by Saudi Arabia (0.354), Oman (0.215), Israel (0.167), Jordan (0.167), Bahrain (0.149), Iran (0.142), Sudan (0.136), Tunisia (0.113), Yemen (0.105), Kuwait (0.101), Lebanon (0.099), Algeria (0.080), Iraq (0.064), Morocco (0.050), Libya (0.030), Palestine Territory (0.030), and Syria (0.030). It is important to note that international internet bandwidth for Egypt and Tunisia, at the forefront of the Arab Spring, has significantly increased during the period.

\section{Discussion}

Based on an empirical analysis of global internet connectedness for the past decade, this study has several important implications for research on social media and political activism. The structural analysis of the global internet network in this study provides an 
important foundation for subsequent behavioral analyses of the role of social media in political movements. While increased global connectedness through the internet is a key assumption of many studies arguing the increased role of social media in political activism, few studies have tested the assumption empirically. This study's network analysis of international internet bandwidth between 2002 and 2010 shows that global internet connectedness has grown significantly during the period and has done so in an interestingly patterned way. While there were variations in terms of countries positioned at the center of the internet network, in general the countries that were central in the 2002 network generally remained so in 2010. These countries include the United States, the United Kingdom, Germany, France, China, Italy, and Singapore. It is likely that connections of those countries will grow faster than those in the periphery of the network.

The rich-getting-richer phenomenon is a commonly observed feature of naturally occurring networks (Barabási, 2002). This has important implications for diplomacy, trade, and global activism in the age of information technology and online social networking. For example, this suggests that countries that use these technologies effectively will, ceteris paribus, gain long-lasting and growing advantages if they do so sooner rather than later.

The results offer insights as to possible contagion effects of political movements. In this networked information society, behaviors of individuals and organizations are often facilitated by characteristics of ICTs systems within which they operate (Benkler, 2011). The fact that a system allows access to high speed and relatively inexpensive networked ICTs has significant implications for governance and spread of movements within and across borders. Networked ICTs, in particular social media, played an 
important role in mobilization and spread of the Occupy Wall Street protests in the United States in 2011 (Ngak, 2011). Activists involved in the recent uprisings in the MENA region in 2010 and 2011 reported that they often relied on internet-based communication tools to exchange ideas and discuss strategies with those in other countries (Kirkpatrick \& Sanger, 2011).

Importantly, several countries in the MENA region have become more central in the global internet network of 2010 than they were in 2002. These include the United Arab Emirates, Qatar, Egypt, and Saudi Arabia. In particular, it is important to note that Egypt has greatly increased its centrality in the network over the past decade. Egypt has become more connected with other countries (degree) and has become increasingly directly connected with important countries within the network (eigenvector centrality). In addition, Tunisia's international internet bandwidth has grown considerably between 2006 and 2010. Does significantly increased internet bandwidth in the MENA region have any direct correlation with recent uprisings in the region? This paper does not test any correlational or causal claims regarding the relationship between internet connections and political movements. However, to the extent network structure enables or facilitates actions, perceptions, and policies, results reported here are consistent with arguments suggesting that more demands for political change may be expected to occur in MENA and that these demands may be patterned after demands expressed elsewhere. Understanding changes in the global internet and how countries in the MENA region have evolved as part of the network is an important step toward understanding political movements in the region. The finding of the study that international internet bandwidth 
within the region has increased provides an important clue as to possible contagion effects of political movements in the region.

\section{Conclusion}

The internet has become an important tool for mobilization, organization, and diffusion of political movements in many parts of the world, and the system-level investigation of the structure of internet helps researchers and scholars better understand changes in the global connectedness brought about by increasingly available and affordable high-speed networks. Network-induced changes have important implications for diplomacy, trade, and global activism. In addition, network concepts and analyses used in this study provide guidance for those wishing to analyze different types of transnational connections among countries and the resultant global network. As Slaughter (2009) put it, "connectedness" is "the measure of power" in this world, and thus it is essential to understand how different types of connections are initiated, developed, and maintained in this network information age.

While this analysis offers several new and interesting findings, it is important that readers be reminded of some limitations of the study. With regard to the analysis of international internet bandwidth, it should be noted that TeleGeography's data set includes only countries whose transnational bandwidth data were available for a given year. This means that direct bandwidth connections between some small countries might have been left out. However, TeleGeography's data set is the most complete dataset available at this point and it includes most, if not all, major international bandwidth connections. 
Future research must analyze relationships between patterns of international internet bandwidth connections and amount and characteristics of political messages people in the MENA region exchanged via social media sites with people within the region and people outside the region. This will help us better understand possible direct connections between systems of ICTs and behavioral aspects related to social media and political movement. In addition, network analysis of individual-level ICTs connections of MENA activists with their counterparts within the region and outside the region will provide useful information to understand political activism in the networked information society. The Occupy Wall Street Movement will also be an interesting topic to study in the area of social media and political activism. Network analysis approaches used in this study may be applied to examine the role of social media in contagion of the movements.

An internet is, of course, a network of networks. As countries develop, they make strategic choices about whether to invest in information infrastructure that routes traffic from their exchange points to those of their immediate neighbors, or whether to invest in information infrastructure that routes traffic from their exchange points to those of more distant countries. Sometimes these decisions are constrained by available resources, and hooking up to an undersea trunk cable that connects to the US, UK, or Europe is almost always a good way to improve the bandwidth available to users. But sometimes these decisions may also be political. The evolution of networks in North Africa and the Middle East suggests that over the last few years, governments have been improving the speed of connections between regional capitals. Where particular digital packets go in a network is almost randomly determined. But improving the bandwidth available between countries in this region, without having the US, UK, or Europe as a mandatory point of 
passage, is evidence of the rising level of investment in an overall communication infrastructure for in-country and within region use.

Finally, we suggest that changes in internet bandwidth capacity serve as observable leading indicators of future communication patterns. Investing in new capacity is expensive and generally requires significant lead-time. Examining these changes provides a useful structural glimpse of anticipated future economic and political context. This can then be used to direct more micro-level research on their behavioral consequences. The point here is that communication behaviors must be interpreted in light of the structures within which they are manifested. Our analysis is intended to demonstrate that those structures themselves have exhibited patterned changes over the past decade. 


\section{References}

Anheier, H., \& Katz, H. (2005). Network approaches to global civil society. In H. Anheier, M. Glasius \& M. Kaldor (Eds.), Global civil society 2004/5. London: Sage.

Barabási, A. (2002). Linked: The New Science of Networks. Cambridge, MA: Perseus Publishing.

Barnett, G. A. (2001). A longitudinal analysis of the international telecommunication network, 1978-1996. American Behavioral Scientist 44(10), 1638-1655.

Barnett, G. A., Chon, B., \& Rosen, D. (2001). The structure of the Internet flows in cyberspace. Networks and Communication Studies, 15, 1-2, 61-80.

Barnett, G. A., \& Park, H. W. (2005). The structure of international Internet hyperlinks and bilateral bandwidth. Annals of telecommunications, 60(9-10), 1115-1132.

Barnett, G. A., \& Sung, E. (2005). Culture and the structure of the international hyperlink network. Journal of Computer-Mediated Communication, 11(1).

Bastian M., Heymann S., Jacomy M. (2009). Gephi: an open source software for explorin g and manipulating networks. International AAAI Conference on Weblogs and So cial Media.

Benkler, Y. (2006). The wealth of networks: how social production transforms markets and freedom. New Heaven and London: Yale University Press.

Benkler, Y. (2011). Networks of power, degrees of freedom. International Journal of Communication 5, 721-755.

Bennett, W. L. (2004). Branded political communication: Lifestyle politics, logo campaigns, and the rise of global citizenship, In M. Micheletti, A. Follesdal, \& D. 
Stolle (Eds.), Politics, Products, and Markets: Exploring Political Consumerism Past and Present. Transaction Books.

Carpenter, C. R. (2007). Setting the advocacy agenda: Theorizing issue emergence and nonemergence in transnational advocacy networks. International Studies Quarterly, 51(1), 99-120.

Castells, M. (1996). The rise of the network society. New York: Blackwell.

Castells, M. (2000). Materials for an exploratory theory of the network society. British Journal of Sociology, 51(1), 5-24.

Castells, M. (2004). Informationalism, networks, and the network society: A theoretical blueprinting. In Castells (Ed.) The network society: a Cross-Cultural Perspective. Northampton, MA: Edward Elgar.

Chadwick, A., \& Howard, P. N. (Eds.). (2009). The Handbook of Internet politics. New York: Rutledge.

Gladwell, M. (2010, October 4). Small change: Why the revolution will not be tweeted. The New Yorker.

Hafner-Burton, E. M., Kahler, M., \& Montgomery, A. H. (2008). Network analysis for international relations. International Organization, 63(3).

Hampton, K. N., Goulet, L. S., Rainie, L., \& Purcell, K. (2011). Social networking sites and our lives. Pew Research Center's Internet \& American Life Project.

Howard, P. N. (2010). The digital origins of dictatorship and democracy: Information technology and political Islam. Oxford: Oxford University Press.

Kirkpatrick, D. D., \& Sanger, D. E. (2011, February 13). A Tunisian-Egyptian link that shoot Arab history. The New York Times. 
Kranzberg, M. (1985). The information age: Evolution or revolution? In B. Guile (Ed.) Information technologies and social transformation. Washington, D.C.: National Academy Press.

Lee, S., Monge, P.R., Bar, F., \& Matei, S. (2007). The emergence of clusters in global telecommunications networks. Journal of Communication, 57, 415-434.

Lichtenstein, J. (2010, July 12). Digital diplomacy. The New York Times.

Monge, P. R., \& Contractor, N. S. (2003). Theories of communication networks. New York: Oxford University Press.

Myers, D. J. (2000). The diffusion of collective violence: Infectiousness, susceptibility, and mass media networks. American Journal of Sociology, 106, 173-208.

Moezzi, M. (2009, December 7). Iran's green revolutionaries pack a powerful punch. NPR. Retrieved from http://www.npr.org/templates/story/story.php?storyId=121052945.

Morozov, E. (2010, February 20). The digital dictatorship. The Wall Street Journal. Retrieved from http://online.wsj.com/article/NA_WSJ PUB:SB100014240527487039830045750 73911147404540.html.

Ngak, C. (2011). Occupy Wall Street users social media to spread nationwide. CBS. Retrieved from http://www.cbsnews.com/8301-501465_162-20117291501465.html.

Newman, M. E. J. (2010). Networks: An introduction. Oxford: Oxford University Press. Nickerson, David W. (2008). Is voting contagious? Evidence from two field experiments. American Political Science Review, 102(1), 49-57. 
R Development Core Team (2011). R: A language and environment for statistical comput ing. R Foundation for Statistical Computing, Vienna, Austria. ISBN 3-900051-070, http://www.R-project.org/.

Rogers, E. M., \& Kincaid, D. L. (1981). Communication networks: Toward a new paradigm for research. New York: The Free Press.

Slaughter, A-M. (2009). America's edge: Power in the networked century. Foreign Affairs, 88(1).

Soete, L., \& Weel, B. T. (2005). The economics of the digital society. Northampton, Mass.: Edward Elgar.

Stohl, C., \& Stohl, M. (2007). Networks of terror: Theoretical assumptions and pragmatic consequences. Communication Theory, 17(2), 93-124.

TeleGeography (2009). Global Internet Geography Executive Summary. Retrieved from http://www.telegeography.com/research-services/global-Internet-geography/.

Townsend, A. M. (2001). Network cities and the global structure of the Internet. The American Behavioral Scientist, 44(10), 1697-1716.

Valente, T. (1993). Diffusion of innovations and policy decision-making. Journal of Communication 43(1), 30-45.

Wasserman, S., \& Faust, K. (1994). Social network analysis: Methods and applications. Cambridge, U.K.: Cambridge University Press.

Watts, D., \& Strogatz, S. (1998). Small world. Nature, 393, 440-442.

Webster, F. (2002). Theories of the information society. New York: Rutledge. 


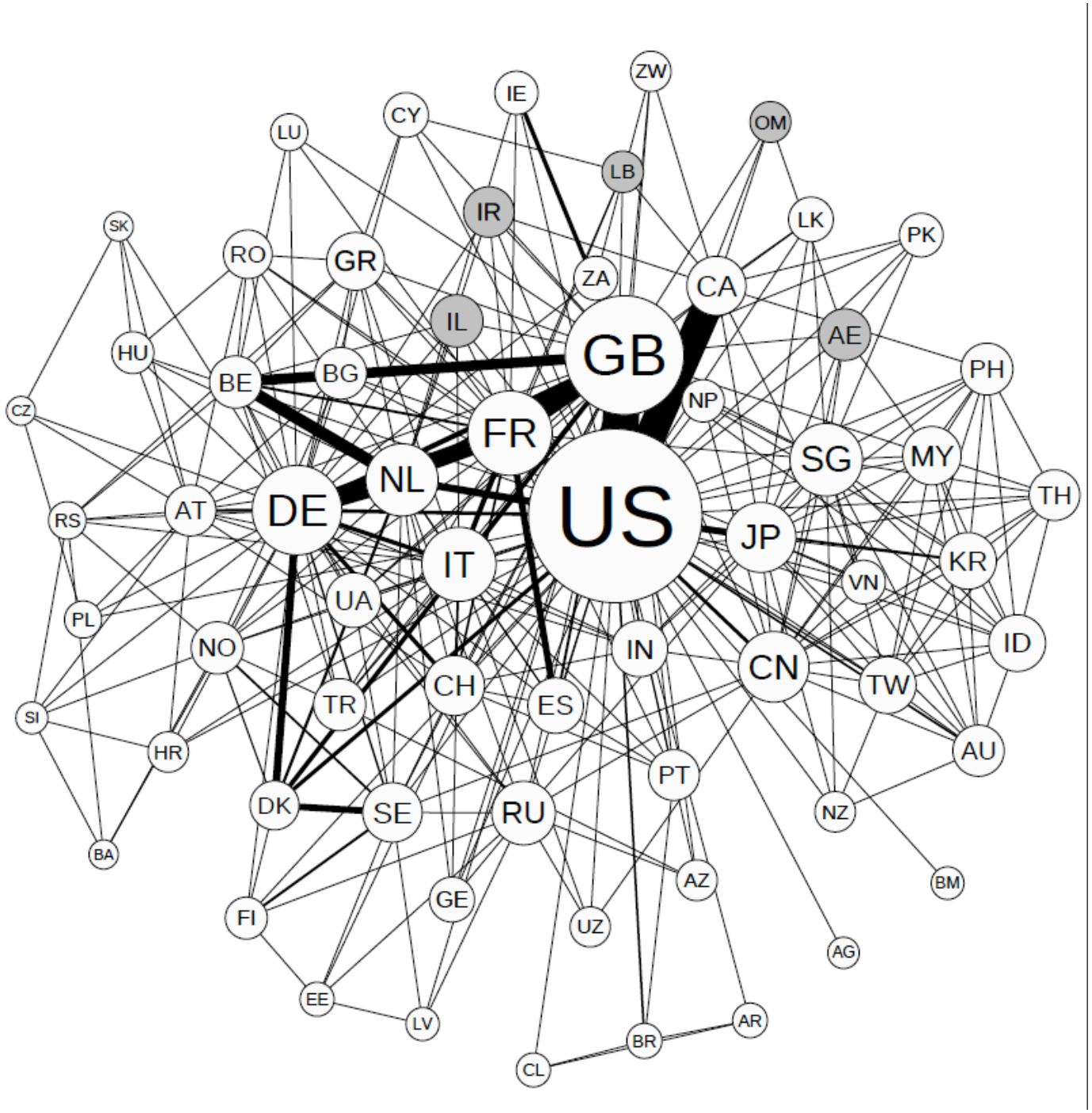

Figure 1 Global Internet Structure in 2002

Note: For brevity of presentation, only countries with connections of degree 4 or greater in are shown in the figure. The diameter of the node is proportional to the node's eigenvector centrality. Nodes in grey represent MENA countries. To denote countries, ISO 3166-1 alpha-2 codes using the English short country names are used. 


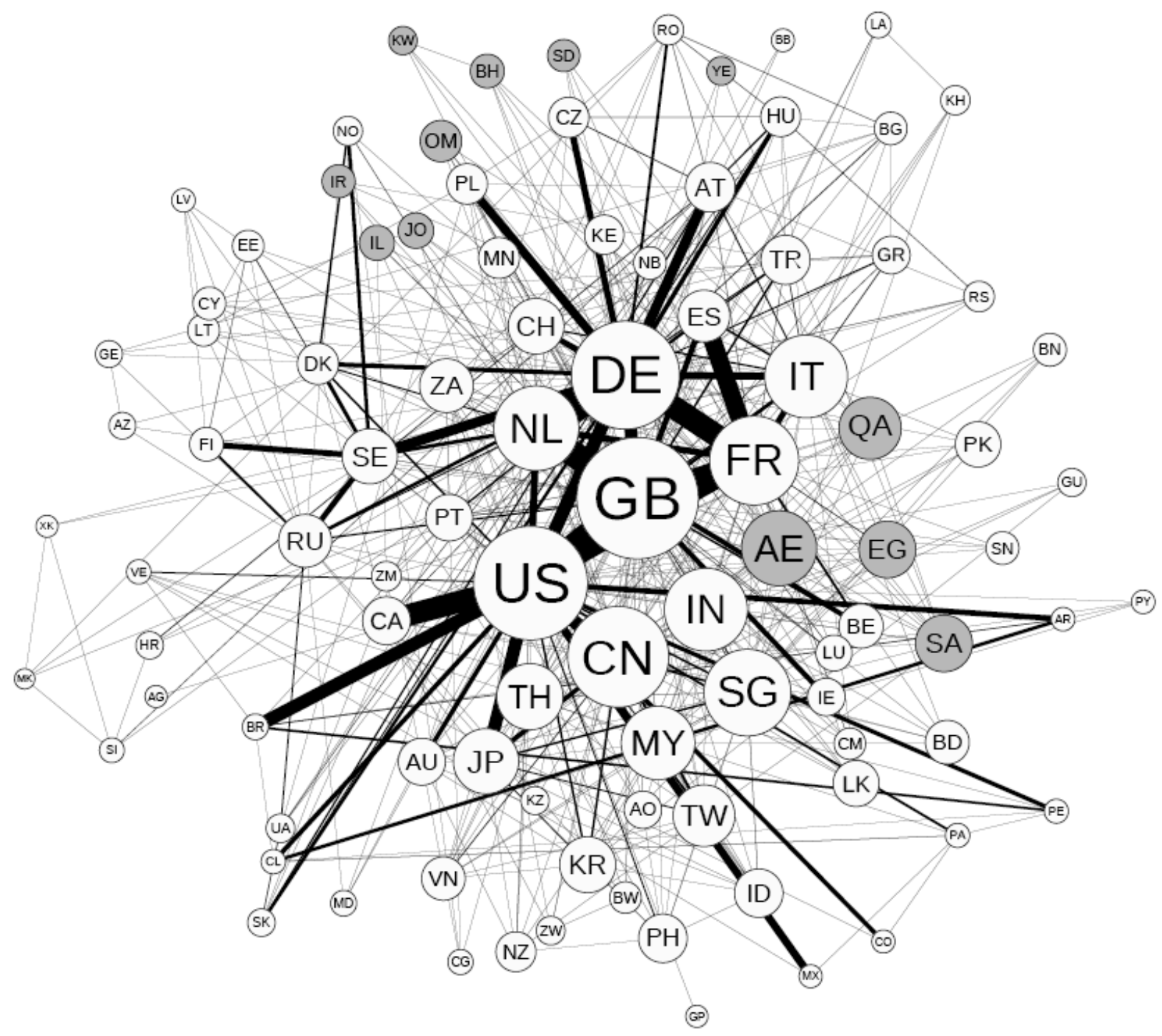

Figure 2 Global Internet Structure in 2010

Note: For brevity of presentation, only countries with connections of degree 4 or greater in are shown in the figure. The diameter of the node is proportional to the node's eigenvector centrality. Nodes in grey represent MENA countries. To denote countries, ISO 3166-1 alpha-2 codes using the English short country names are used. 


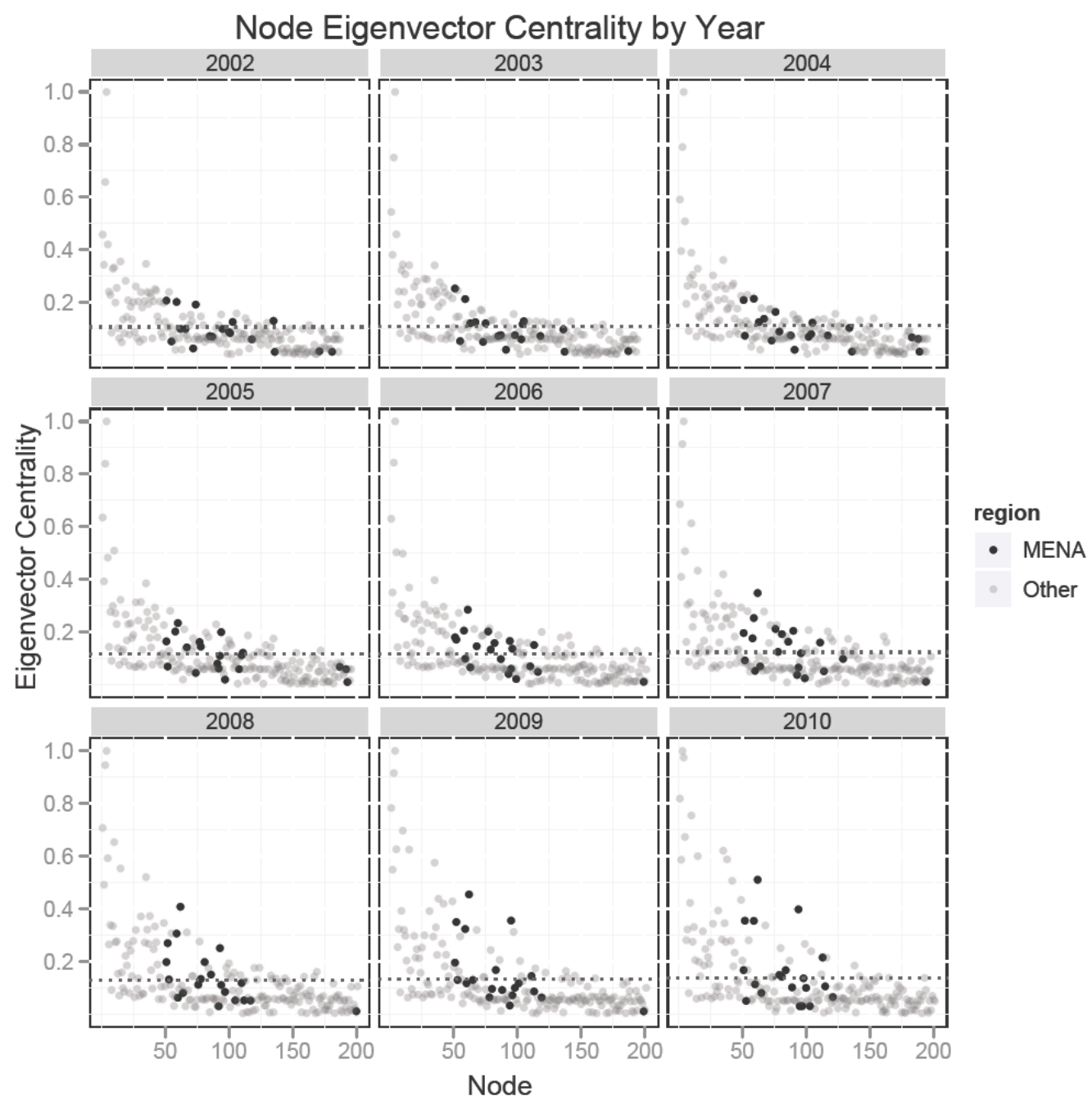

Figure 3 Node eigenvector centrality 2002-2010 


\section{ENDNOTES}

${ }^{1}$ The MENA countries analyzed in this study include Algeria, Bahrain, Egypt, Iran, Iraq, Israel, Jordan, Kuwait, Lebanon, Libya, Morocco, Oman, Palestine Territory, Qatar, Saudi Arabia, Sudan, Syria, Tunisia, the United Arab Emirates, and Yemen. 